\title{
WHEN I AM COMING TO TERMS THEY COME
}

When I am coming to terms they come, and I watch them slosh by the window. This is a wooden block of time which

blackens at sky and ground.

We can't stop winding up

yelling from the backs

of trucks, on our way

to one border or another. I can't

keep tracks; they flee from me.

I have forgotten the range

of our instruments. Today

they only crane their necks to stare,

refuse to make sound: the cello balking

at the double-stop; the trumpet

bowed over, clutching its mute.

Tonight I'm sitting, trying to coax the piano

into articulating its complaint.

The keys stubborn. Each wait

between notes just sprays us

with want. We stab at maps,

with sucked-on fingers. The silence

is landlocking.

I am merging onto several highways.

I am, in principle, open to strangers.

Still the spaces keep growling for something. 
Tonight down skinny streets in a city, all the adults are doubled over the cobbles, laughing or crying I'm not quite sure;

I've forgotten how to get close.

Instead I bob up and down like a meerkat, peering into letterboxes and down and down dresses; sometimes I fall over myself, and this can no longer be

an accident. We shouldn't be standing at an ATM.

We shouldn't drink from rivers shouldn't fill ourselves with thoughts of giardia crawling through our bodies'

linings. Still, there's only a snatch of a minute left till my mind reverts back to its mirrorings.

I only hope in the interim something may've snapped.

I look out, and the terms are still sloshing by our window, past cobwebs nestled in hedges like fog. Barely there.

I fashion some antlers

to guard my brain. I fashion some worlds built of bits of sound I've captureda radio's bristling; a sticky lock's turning; bare cough 
from the last truck out of the forest-and I keep the thought (the hope?) that these sounds, these small attempts at breath, might hold us. 